\title{
Effects of Eriobotrya japonica (Lindl.) flower extracts on mercuric chloride-induced hepatotoxicity in rats
}

\author{
ESMAEILI Amir Hossein ${ }^{1 *}$, KHAVARI-NEJAD Ramazan Ali ${ }^{1}$, \\ HAJIZADEH MOGHADDAM Akbar ${ }^{2}$, CHAICHI Mohammad Javad ${ }^{3} \&$ \\ EBRAHIMZADEH Mohammad $\mathrm{Ali}^{4}$ \\ ${ }^{1}$ Department of Biology, Science and Research Branch, Islamic Azad University, Box 14515-775, Tehran, Iran; \\ ${ }^{2}$ Faculty of Basic Science, University of Mazandaran, Box 47416-95448, Babolsar, Iran; \\ ${ }^{3}$ Faculty of Chemistry, University of Mazandaran, Box 47416-95447, Babolsar, Iran; \\ ${ }^{4}$ Pharmaceutical Sciences Research Center, School of Pharmacy, Mazandaran University of Medical Sciences, Sari 48189, Iran
}

Received February 29, 2012; accepted March 23, 2012

\begin{abstract}
Mercury (II) is an important factor in hepatotoxicity that can enter the body through marine diets and amalgams. In the present study, the protective effect of the Eriobotrya japonica flower extract (EJFE) on $\mathrm{HgCl}_{2}$-induced hepatotoxicity was investigated. Five $\mathrm{mg} / \mathrm{kg}$ of mercuric chloride in drinking water was given to rats either with saline or EJFE (100 and $200 \mathrm{mg} / \mathrm{kg}$ as intraperitoneal (IP)) for $30 \mathrm{~d}$. The mercury levels in different groups of liver tissues of the rats were measured with flameless atomic absorption spectroscopy (F-AAS). Also, mercury accumulation in the liver of the rats was modeled by using a parallel chemical kinetic model. The results showed that $\mathrm{HgCl}_{2}$-induced oxidative damage led to a significant decrease in glutathione (GSH) and the total antioxidant capacity (TAC) levels, and to a significant increase in lipid peroxidation level. Accumulated mercury was $14.47 \%$ more in the livers of the stress groups than in those of the control groups $(P<0.001)$, whereas the amount of $\mathrm{Hg}$ was adjusted to $13.49 \%$ and $13.93 \%$ in groups treated with 100 and $200 \mathrm{mg} / \mathrm{kg}$ of EJFE respectively, as compared with stress groups $(P<0.001)$. HPLC analysis of EJFE revealed that hesperetin and gallic acid are the major antioxidants in EJFE. Results demonstrate that flowers of the Eriobotrya japonica cause a significant protection against $\mathrm{HgCl}_{2}$ induced hepatotoxicity in all diagnostic parameters by strengthening the antioxidant defense mechanisms and they may have a therapeutic function in free radical mediated diseases.
\end{abstract}

mercury, oxidative stress, hepatotoxic, Eriobotrya japonica, antioxidant

Citation: Esmaeili A H, Khavari-Nejad R A, Hajizadeh Moghaddam A, et al. Effects of Eriobotrya japonica (Lindl.) flower extracts on mercuric chloride-induced hepatotoxicity in rats. Chin Sci Bull, 2012, 57: 3891-3897, doi: 10.1007/s11434-012-5429-z

Mercury (II) salts are usually more toxic than mercury (I) because their solubility in water is higher. Thus, they are more readily absorbed by the gastrointestinal tract. Since the liver is the body detoxification center, $\mathrm{Hg}$ can cause damages in it [1]. Mercury (II) is a potential hepatotoxic agent and oxidative stress is its major cause [2]. Studies show that Gilbert's Syndrome is a liver damage caused by mercury amalgam. Oxidative stress and reactive oxygen species (ROS) are responsible for $\mathrm{HgCl}_{2}$-induced cytotoxi-

*Corresponding author (email: amir5762002@yahoo.com) city [3]. Mercury induced oxidative stress has an important contribution to molecular mechanism liver injury [4]. Mercuric chloride as $\mathrm{Hg}^{2+}$ has a great affinity for thiol groups $(-\mathrm{SH})$ of endogenous biomolecules [2]. Thus, it is invariably found in cells and tissues attached to thiol-containing proteins and small molecular weight thiols such as cysteine and glutathione (GSH). Mercuric chloride leads to attenuation of antioxidant capacity together with depleting GSH, and inhibiting the activities of antioxidant enzymes in tissues of rats [5,6]. In liver, GSH is conjugated with solvents, fat-soluble pesticides, toxic chemicals and other xenobiotics 
such as mercury. It may end up decreased glutathione levels, an increase to ROS such as superoxide anion radical, hydrogen peroxide and hydroxyl radical [7], which induce lipid, protein, and DNA oxidation. Mercury exposure induces lipid peroxidation detected by increasing thiobarbituric acid reactive substances (TBARS) in tissues of kidneys, liver and brain in rats [8]. Moreover, $\mathrm{HgCl}_{2}$-induced injury can be ameliorated by enzymatic antioxidants such as superoxide dismutase, catalase and glutathione peroxidase [9] and non-enzymatic antioxidants such as plant antioxidants. Mercury is proven to be a potential oxidant in the category of environmental factors. Therefore, there is a need to provide protection against mercury induced toxicity. Nutritional plant supplements play a vital role in GSH metabolism through their participation in the glutathione peroxidase cycle. Eriobotrya japonica (Lindl.) is a fruit tree in the Rosaceae family, indigenous to southeastern China and Japan. Now it is also cultivated in the Mediterranean areas, Australia, South Africa, South America, California, India and north of Iran. Its white flowers turn to pale-yellow or deep-orange pomes [10]. Its leaves have been used for treatment of skin diseases and diabetes [11], chronic bronchitis, coughs, phlegm, ulcers and cancer [12]. Eriobotrya japonica (Loquat) is full of phenolics and antioxidant compounds [13]. Flavonoids and phenolic compounds are secondary metabolites, affluent in the plant kingdom and effective in human health, and decrease the risk of several diseases by reducing oxidative stress [14]. A few studies have been reported that extracts of flowers from the Eriobotrya japonica have antioxidative and protective effects. However, the effects of EJFE on liver damage and oxidative defects due to mercuric chloride are unknown. In this study, hydro-alcoholic extract of the Eriobotrya japonica flowers is proved to possess a significant free radical scavenging capacity and exert a protective effect against $\mathrm{HgCl}_{2}$ mediated hepatotoxicity.

\section{Materials and methods}

\subsection{Reagents and chemicals}

Hesperetin was purchased from Sigma (Steinheim, Germany). Gallic acid was purchased from Acros (Geel, Belgium). HPLC grade methanol was purchased from Fluka (Buchs, Switzerland). Ethanol was from Merck (Darmstadt, Germany). Sulfanilamide, $\mathrm{FeCl}_{2}, \mathrm{FeCl}_{3}$, bovine serum albumin (BSA), 2,4,6-tri-pyridyl-S-triazine (TPTZ), 5,5'-dithiobis (2-nitrobenzoic acid) (DTNB), butylated hydroxy anisole (BHA) and ethylenediaminetetraacetic acid (EDTA) were purchased from Sigma-Aldrich (St. Louis, MO, USA). All Millipore syringe filters $(0.22$ and $0.45 \mu \mathrm{m})$ were purchased from Millipore Company (JET BIOFIL ${ }^{\circledR}$ Syringe Driven Filters). Water used was double distilled and deionized. Other chemicals were purchased from Sigma-Aldrich. Reagents used were of the highest commercially available purity.

\subsection{Methods}

(i) Preparation of the extract for HPLC. Extraction procedure was performed according to the method proposed by Hertog et al. [15]. Briefly, $0.5 \mathrm{~g}$ of sample was refluxed using $50 \mathrm{~mL}$ of $50 \%$ aqueous methanol at $90^{\circ} \mathrm{C}$ for $2 \mathrm{~h}$. This solution contains $1.5 \mathrm{~g} / \mathrm{L}$ of BHA in order to prevent the analytes from oxidation. The obtained extracts were cooled and filtered to remove solid particles, then filtered by a $0.45 \mu \mathrm{m}$ syringe Millipore filters and injected into the HPLC system.

(ii) HPLC system. The chromatographic measurements were carried out with HPLC system which consisted of a model 515 solvent delivery system equipped with model $7725 \mathrm{i}$ injector fitted with a $20 \mu \mathrm{L}$ loop. The column used was Spherisorb C18 (250×4.6 mm; particle size, $\phi 5 \mu \mathrm{m})$ from Waters (Milford, MA, USA). The UV detector was model LC-95 set at $260 \mathrm{~nm}$. The mobile phase used for separation and determination of analytes was methanol:0.4\% phosphoric acid $(42.5 / 57.5, \mathrm{v} / \mathrm{v})$ containing THF $(0.5 \%)$ as organic modifier with flow rate of $1 \mathrm{~mL} / \mathrm{min}$ at $30^{\circ} \mathrm{C}$. Determination of gallic acid and hesperetin in EJFE was performed by using standard addition method with HPLC at $260 \mathrm{~nm}$. Identification of each compound was performed by its retention time and spiking with the standard.

\subsection{Preparation of the extract for in vivo studies}

Eriobotrya japonica flowers were collected freshly in gardens around Ghaemshar, Mazandaran, Iran in Octobr 2010. In outset, plant flowers were exposed to the shadows for two weeks and in oven at $37^{\circ} \mathrm{C}$ for $1 \mathrm{~d}$ and then were pulverized. About $81.5 \mathrm{~g}$ of the powders of these flowers were shaked and extracted with hydro-alcoholic $(25: 75$, v/v) exhaustively. Next, filtered with Whatman filter paper and concentrated to dryness under reduced pressure in a rotary evaporator at $30^{\circ} \mathrm{C}$ for $6 \mathrm{~h}$ to yield dried hydro-alcoholic extract, $9.52 \%(\mathrm{w} / \mathrm{w})$.

\section{4 vivo experimental design}

Adult male Wistar rats weighing 200-230 g, procured from Pasteur Institute Amol, Mazandaran, Iran, were used throughout this study. Animals were acclimatized to the laboratory conditions at room temperature prior to the experimentation. Animals were kept under standard conditions of a $12 \mathrm{~h}$ light/dark cycle with free access to water and pellet diets. The protocol was approved by the Institutional Animal Ethics Committee in Mazandaran University, Babolsar, Iran. Rats were divided into six groups, and each consisted of six animals. Group I served as control (saline, $0.9 \% \mathrm{NaCl}$, intraperitoneally, IP). Other groups are: group II (control+100 EJFE); group III (control+200 EJFE); group IV (Hg group); group $\mathrm{V}(\mathrm{Hg}+100 \mathrm{EJFE})$ and group VI $(\mathrm{Hg}+200 \mathrm{EJFE})$. Following of $5 \mathrm{mg} / \mathrm{kg}$ mercuric chloride $\left(\mathrm{HgCl}_{2}\right)$ in drinking water either saline or EJFE (100 and $200 \mathrm{mg} / \mathrm{kg}$ as IP) was 
administered for $30 \mathrm{~d}$. The dosage of mercuric chloride has been determined based on the study of Sener et al. [16] as sufficient to elicit mild to wide oxidative stress, while EJFE similar to the study of Sener et al. [17], 100 and $200 \mathrm{mg} / \mathrm{kg}$, is effective to the antioxidant effects. Eriobotrya japonica used in this study comes as an extract from the flowers of the plant and contains hesperetin (as bioflavonoid) and gallic acid, the major antioxidants present in it. After $24 \mathrm{~h}$ of treatment, rats were sacrificed; their livers were isolated for post-mitochondrial supernatant (PMS) preparation.

\subsection{Post-mitochondrial supernatant (PMS) preparation}

Livers were removed and rinsed with ice-cold isotonic saline and homogenized with ice-cold phosphate buffer $(50 \mathrm{mmol} / \mathrm{L}$, $\mathrm{pH}$ 7.4) containing potassium chloride $(1.17 \%$, w/v) by using a Potter Elvehjem homogenizer. The homogenate $(10 \%, \mathrm{w} / \mathrm{v})$ was centrifuged at $800 \times g$ for $5 \mathrm{~min}$ to separate the nuclear debris. Then, the supernatant was centrifuged at $10000 \times g$ for $20 \mathrm{~min}$ at $4^{\circ} \mathrm{C}$ (Hettich model universal 320RZENTRIFUGEN, Germany) to obtain PMS for the biochemical enzymatic estimations.

\subsection{Total antioxidant capacity (TAC) in liver}

TAC in liver supernatant was estimated by the Ferric Reducing Antioxidant Power (FRAP) method [18]. The FRAP reagents consisted of $300 \mathrm{mmol} / \mathrm{L}$ acetate buffer ( $\mathrm{pH} 3.6), 10$ $\mathrm{mmol} / \mathrm{L} \mathrm{TPTZ} \mathrm{in} 40 \mathrm{mmol} / \mathrm{L} \mathrm{HCl}$ and $20 \mathrm{mmol} / \mathrm{L} \mathrm{FeCl}_{3} \cdot 6 \mathrm{H}_{2} \mathrm{O}$ (the ratio is $10: 1: 1)$. Briefly, the supernatant of liver $(25 \mu \mathrm{L})$ was added to $1.5 \mathrm{~mL}$ of the freshly prepared FRAP reagent solution pre-warmed at $37^{\circ} \mathrm{C}$ and then incubated at $37^{\circ} \mathrm{C}$ for $10 \mathrm{~min}$. The absorbance values or standard was recorded at $593 \mathrm{~nm}$ against the reagent blank $(1.5 \mathrm{~mL}$ of the FRAP reagent $+25 \mu \mathrm{L}$ of distilled water). Standard $\mathrm{FeCl}_{2} \cdot 4 \mathrm{H}_{2} \mathrm{O}$ solutions $(25-2000 \mu \mathrm{mol} / \mathrm{L})$ were prepared by distilled water. The FRAP value was expressed as $\mu$ mole reduced ferric ion to ferrous form on the basis calibration curve of standard of $\mathrm{FeCl}_{2} \cdot 4 \mathrm{H}_{2} \mathrm{O}$.

\subsection{Measurement of lipid peroxidation}

The extent of lipid peroxidation in the liver was quantitatively determined by estimation malondialdehyde (MDA) $[19,20]$. The amount of MDA was measured by reaction with thiobarbituric acid (TBARS) at $532 \mathrm{~nm}$ by the use of T80/T80 ${ }^{+}$UV/Vis Spectrophotometer (PG Instruments Limited, Beijing, China). The values were calculated using the molar extinction co-efficient of chromophore $\left(1.56 \times 10^{5}\right.$ $\mathrm{mol}^{-1} \mathrm{~L} \mathrm{~cm}^{-1}$ ). The concentration of TBARS was expressed as nmoles of MDA per mg of tissue proteins.

\subsection{Estimation of reduced glutathione}

Reduced glutathione in the liver homogenized was estimated according to the method described by Ellman [21]. One millilitre aliquot of liver PMS $(10 \%, \mathrm{w} / \mathrm{v})$ was precipitated with $1 \mathrm{~mL}$ of $4 \%$ sulphosalicylic acid and digested in cold conditions for $1 \mathrm{~h}$ at $4^{\circ} \mathrm{C}$. Then, the samples were centrifuged at $1200 \times \mathrm{g}$ for $15 \mathrm{~min}$ at $4^{\circ} \mathrm{C}$. Next, $0.1 \mathrm{~mL}$ of the supernatant was obtained; $2.7 \mathrm{~mL}$ of phosphate buffered saline (100 $\mathrm{mmol} / \mathrm{L}, \mathrm{pH} 7.4)$ and $0.2 \mathrm{~mL}$ of DTNB $(40 \mathrm{mg} / 10 \mathrm{~mL}$ of phosphate buffered saline, $0.1 \mathrm{~mol} / \mathrm{L}, \mathrm{pH} 7.4$ ) was added. The yellow color developed was measured at $412 \mathrm{~nm}$. Results were calculated by using the molar extinction co-efficient of the chromophore $\left(1.36 \times 10^{4} \mathrm{~mol}^{-1} \mathrm{~L} \mathrm{~cm}^{-1}\right)$. GSH contents were expressed as nmoles of GSH per $\mathrm{mg}$ of tissue proteins.

\subsection{Mercury estimation in liver tissues}

Determination of mercury in liver tissues by flameless atomic absorption spectroscopy (F-AAS) is described on the base of references [22,23]. The absorption of metallic mercury was measured by an atomic absorption spectrophotometer flame and graphite analysis (PG Instruments Ltd, 990 model) set at $253.7 \mathrm{~nm}$ in Medical Science of Babol University, Mazandaran, Iran. To determine the levels of mercury in liver tissues, standard curves of mercury in the range $5-1000 \mu \mathrm{g} / \mathrm{mL}$ that prepared daily of mercury standard solution $(1000 \mu \mathrm{g} / \mathrm{mL})$ were used. Then, the total concentration of mercury was calculated in $\mu \mathrm{g} / \mathrm{g}$ of tissue.

\subsection{Modeling of mercury accumulation in liver tissues}

Mercury accumulation was modeled by a parallel chemical kinetic model $[24,25]$. The kinetic model can be described by the following equation:

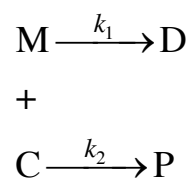

where, $\mathrm{M}$ and $\mathrm{C}$ are mercury and EJFE species respectively, $\mathrm{D}$ and $\mathrm{P}$ are the products. So, the mass balance equation for this chemical reaction system can be written as follows:

$$
\frac{\mathrm{d} M}{\mathrm{~d} t}=m_{\mathrm{in}}-k_{1} M-k_{2} M C^{n}=m_{\mathrm{in}}-\left(k_{1}+k_{2} C^{n}\right) M
$$

where, $M$ is mercury concentration $(\mathrm{mg} / \mathrm{kg} \mathrm{b} . \mathrm{w})$ in tissues, $m_{\text {in }}$ is mercury ingestion daily ( $\left.\mathrm{mg} / \mathrm{kg} \mathrm{b.w}\right), C$ is EJEF concentration ( $\mathrm{mg} / \mathrm{kg} \mathrm{b.w}), n$ is the reaction order and $t$ is the time (d). This differential equation can be solved by using the integral factor. The general solution of this differential is as follows:

$$
M e^{\left(k_{1}+k_{2} C^{n}\right) t}=\frac{m_{\text {in }}}{\left(k_{1}+k_{2} C^{n}\right)} \mathrm{e}^{\left(k_{1}+k_{2} C^{n}\right) t}+\text { cons. }
$$

And by using the initial conditions, the exact solution is: 


$$
\begin{gathered}
\left\{\begin{array}{l}
t=0 \\
M=0.972 \mathrm{mg} / \mathrm{kg} \text { b.w }
\end{array} \Rightarrow M=0.972 \mathrm{e}^{-\left(k_{1}+k_{2} C^{n}\right) t}\right. \\
+\frac{m_{\mathrm{in}}}{\left(k_{1}+k_{2} C^{n}\right)}\left(1-\mathrm{e}^{\left(k_{1}+k_{2} C^{n}\right) t}\right)
\end{gathered}
$$

The initial conditions were based on the initial concentration of mercury in the liver. The three parameters in eq. (4) i.e. $k_{1}, k_{2}, n$ were estimated using the experimental data by nonlinear curve fitting. The nonlinear least-square solver (lsqnonlin) in optimization Toolbox of MATLAB ${ }^{\circledR}$ was used for parameter estimations. The value of parameters was estimated as follows: $k_{1}=3.553, k_{2}=0.559, n=0.173$.

\subsection{Statistical analysis}

Data was analyzed using the software program SPSS V.16 for Windows. Differences between groups were calculated using one way analysis of variance (ANOVA), followed by LSD comparison to calculate significance. Values of $P<0.05$ were regarded as significant. All data were expressed as means \pm SE.

\section{Results and discussion}

\subsection{HPLC analysis of EJFE}

The Eriobotrya japonica extraction yielded was about $9.52 \%$ (w/w) with hydro-alcoholic extract. We performed HPLC analysis of EJFE to identify some of the flavonids and phenolic compounds. Typical chromatogram of standards of gallic acid and hesperetin (A) and Eriobotrya japonica extract (B) is shown in Figure 1. Several peaks were observed in the HPLC chromatogram. A major peak was obtained at a retention time of $2.85 \mathrm{~min}$ and was identified as gallic acid. Other prominent peak was obtained at retention time of 16.0 min and was identified as hesperetin (bioflavonoid). Concentrations of gallic acid and hesperetin in this sample were 7.2 and $15.6 \mathrm{~g} / \mathrm{kg}$ respectively.

Statistical analysis was performed for validation of determination of analytes in standards (Table 1). Limit of detection (LOD) was calculated on the basis of " $3 S_{\mathrm{b}} / m$ " where $S_{\mathrm{b}}$ is the standard deviation of the blank and is equal to P-P noise when only mobile phase was passing through the column for $45 \mathrm{~min}$ and $m$ is the slope of calibration curve. Linear dynamic range (LDR) was obtained by plotting the peak areas versus concentration and the relative standard deviation (RSD\%) was determined by analyzing standard solutions $(20 \mu \mathrm{g} / \mathrm{mL})$ and repeated five times.

A high yield of polyphenols in the extract indicated that it has possessed a high antioxidant activity. Variations in contents of total phenolics, flavonoids and antioxidant activities in the leaves of eleven Eriobotrya species have been reported by Hong et al. [26].

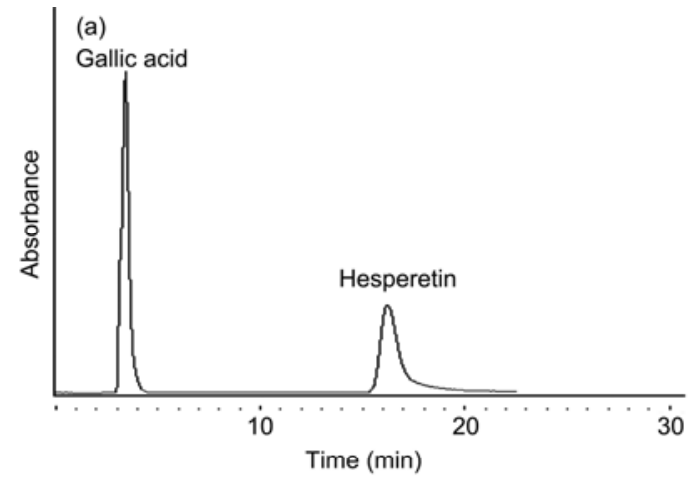

(b)

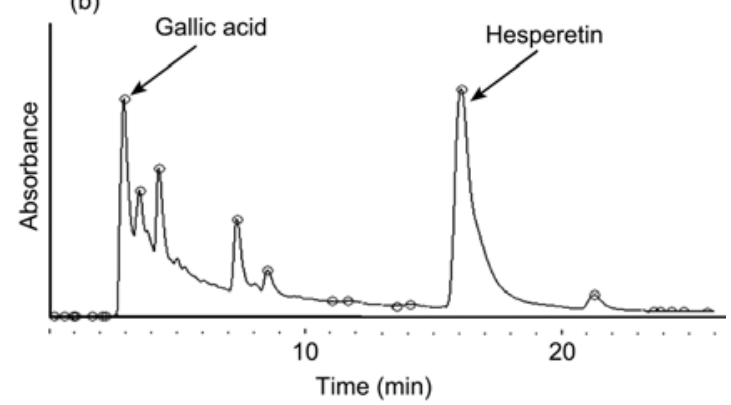

Figure 1 HPLC chromatogram of standards of gallic acid and hesperetin (a) and Eriobotrya japonica flower extracts (EJFE) (b).

Table 1 Statistical results for validation of determination of gallic acid and hesperetin in standards ${ }^{\text {a) }}$

\begin{tabular}{ccccc}
\hline Compound & LOD $(\mu \mathrm{g} / \mathrm{mL})$ & $\mathrm{LDR}(\mu \mathrm{g} / \mathrm{mL})$ & $R^{2}$ & $\mathrm{RSD} \%$ \\
\hline Gallic acid & 0.07 & $0.07-35$ & 0.999 & 1.22 \\
Hesperetin & 0.03 & $0.03-50$ & 0.999 & 2.2 \\
\hline
\end{tabular}

a) LOD, limit of detection; LDR, linear dynamic range; $R^{2}$, regression coefficient; RSD, relative standard deviation. Experiments were repeated five times.

2.2 Effect of EJFE on liver lipid peroxidation (LPO), TAC and reduced glutathione levels (GSH) in rats treated by mercuric chloride

Figure 2 shows that administration of mercuric chloride causes marked decrease in TAC through free radical generation (a), decrease of reduced GSH level (b) and significant increase in liver MDA level (c) as compared to control rats $(P<0.05)$. However, the treatment of rats with EJFE restored GSH contents and TAC, and significantly prevented the increase in MDA level in comparison with stress rats (Figure 2).

\subsection{Concentration of $\mathrm{Hg}$ in rat liver tissues of different groups}

Mercury concentrations in liver tissues of different groups are shown in Figure 3. Administration with mercuric chloride in stress groups $(\mathrm{Hg})$ significantly increased $\mathrm{Hg}$ concentrations $(P<0.001)$ in comparison with the control groups (C). EJFE treatment with chelatoring and neutralizting 

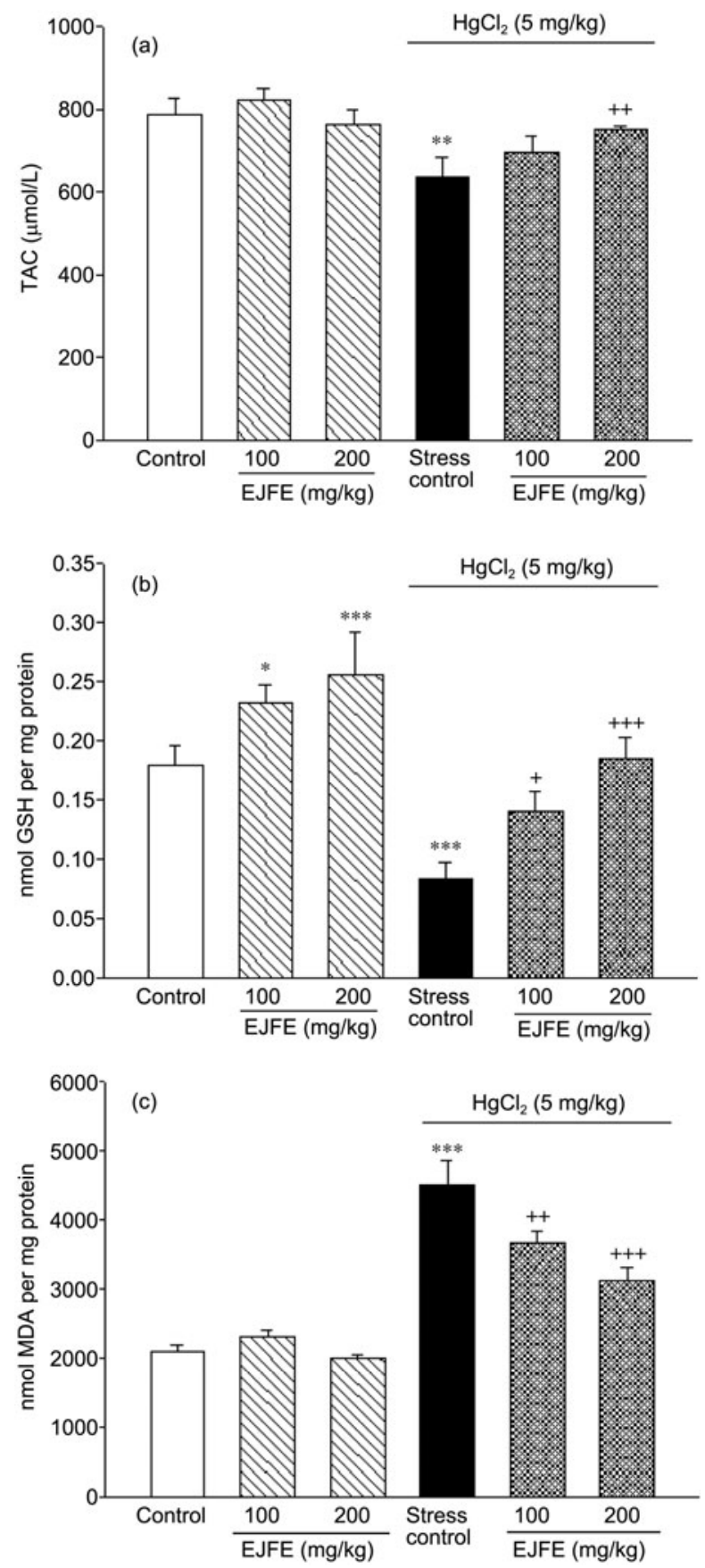

Figure 2 TAC (a), glutathione (GSH) (b) and malondialdehyde (MDA) (c) levels in the liver tissues of saline- or EJFE-treated control and $\mathrm{Hg}$ groups. Each group consists of six rats. ${ }^{*} P<0.05,{ }^{* *} P<0.01,{ }^{* * *} P<0.001$ compared to control group. ${ }^{+} P<0.05,{ }^{++} P<0.01,{ }^{+++} P<0.001$ compared to stress control with mercuric chloride.

activities could cause significant decreases $(P<0.001)$ in $\mathrm{Hg}$ levels in comparison with stress groups.

\subsection{Modeling of mercury accumulation in liver tissues}

Figure 4 shows the simulation of mercury accumulation with time in different concentration of EJEF.

It can be seen that the concentration of mercury levels in

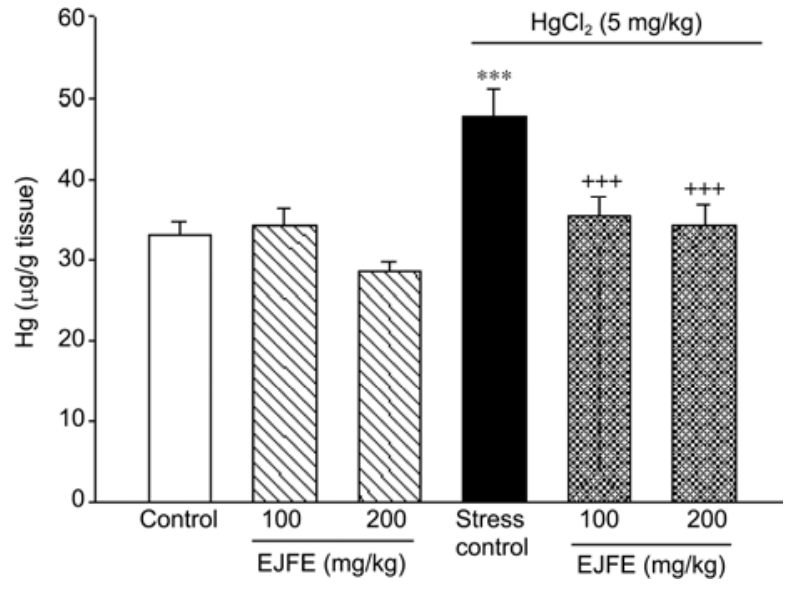

Figure 3 Mercury concentrations in liver tissues of different groups: saline- or EJFE-treated control and $\mathrm{Hg}$ groups. The evaluations have been taken by Flamless-AAS method. The total concentration of mercury was calculated in $\mu \mathrm{g} / \mathrm{g}$ of tissues. Each group consists of six rats $(n=6) .{ }^{*} P<0.05$, ${ }^{* *} P<0.01,{ }^{* * *} P<0.001$ compared to control group. ${ }^{+} P<0.05,{ }^{++} P<0.01,{ }^{+++} P<$ 0.001 compared to stress control with mercuric chloride.

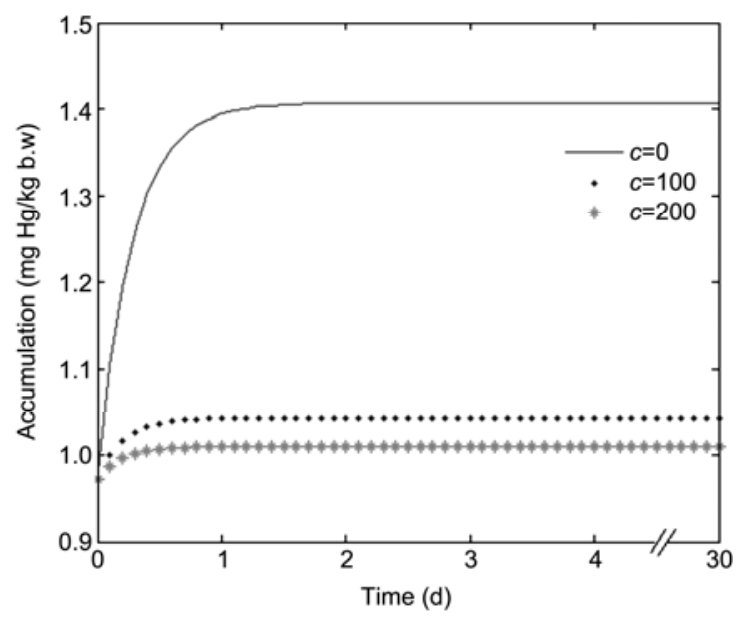

Figure 4 Simulation of accumulation of mercury in liver tissues without EJFE $(c=0)$, and with EJFE in different concentrations $(c=100 \mathrm{mg} / \mathrm{kg}$ b.w, $c=200 \mathrm{mg} / \mathrm{kg} \mathrm{b.w})$.

the tissues reaches to constant levels $(1.40 \mathrm{mg} / \mathrm{kg} \mathrm{b} . \mathrm{w})$ in a few days. The constant levels for mercury concentration in the presence of 100 and $200 \mathrm{mg} / \mathrm{kg}$ of EJEF were 1.0427 and $1.0093 \mathrm{mg} / \mathrm{kg}$ body weight respectively. So, EJEF decreases the mercury accumulation in the tissues significantly. Furthermore, the required time for taking these constant levels are higher than the case without EJEF. This period is $3.1 \mathrm{~d}$ for the case in which EJEF was not ingested. While, they are 1.5 and $1.3 \mathrm{~d}$ for the case of 100 and $200 \mathrm{mg} / \mathrm{kg}$ of EJEF respectively. In other words, this time is different in various ingested concentration of EJEF too.

It is known that mercury (II) is a highly toxic metal which induces oxidative stress in the body [27,28]. Lipid peroxidation [8,29], attenuation of antioxidant defense depleting GSH and inhibiting the activities of antioxidant enzymes occur in the liver, kidney and other tissues of mice 
under $\mathrm{HgCl}_{2}$ [5]. ROS are mediators of tissue damages in several animal species due to $\mathrm{HgCl}_{2}$. Because of the low activity of antioxidant enzymes and GSH contents in the liver, it is assumed that the liver can be extremely sensitive to oxidative stress caused by heavy and toxic metals. Abundant plant extracts/compounds have been shown to improve tissue damages by their antioxidant qualities [24,30,31]. Phenols and polyphenolic compounds, such as flavonoids, are widely found in food products derived from plant sources, and they have been shown to possess significant antioxidant activities $[32,33]$. In the present study, we have shown that Eriobotrya japonica flower extracts (EJFE) have a potential antioxidant activity and protect against $\mathrm{HgCl}_{2}$ induced hepatotoxicity. Phytochemical analysis of Eriobotrya japonica has shown the presence of a number of compounds having antioxidant activity. The HPLC-DAD-ESI-MS/MS screening of the hydro-methanolic extracts of loquat leaves, peel and flesh revealed the presence of several phenolic compounds, mostly hydroxycinnamic acid derivatives and flavonoid glycosides [13]. But, as far as we know, on the Eriobotrya japonica flowers no study has been conducted. We have shown that HPLC analysis of EJFE revealed that hesperetin as bioflavonoid and gallic acid are the major antioxidants. There is a relationship between antioxidant activities and the contents of total phenolics or flavonoids. Also, Yokota et al. [34] reported scavenging activity of ROS by Eriobotrya japonica seed extracts. Scavenging of $\mathrm{H}_{2} \mathrm{O}_{2}$ by EJFE may be attributed to their phenolic compounds (gallic acid) which can donate electrons to $\mathrm{H}_{2} \mathrm{O}_{2}$, neutralizing it to $\mathrm{H}_{2} \mathrm{O}$ and $\mathrm{O}_{2}$. Since $\mathrm{H}_{2} \mathrm{O}_{2}$ can pass membranes and oxidize a number of cell compounds, elimination of hydrogen peroxide as well as the $\mathrm{OH}$ radical is important for both human health, food and drug. Free radical scavenging potential of the EJFE might also be involved in its protective activities against $\mathrm{HgCl}_{2}$ induced hepatotoxicity. In the study of Alia et al. [35] the protective effects of grape antioxidant dietary fibers on the TAC and the activity of liver antioxidant enzymes in rats submitted to acute oxidative stress induced by acetaminophen showed no changes in TAC, and GSH and activities of the other antioxidant enzymes have been associated with an increase of the steady-state activity of glutathione peroxidase. In the present study, increaseing in lipid peroxidation and mercuric tissue content due to administration of mercuric chloride were accompanied by significant reductions in TAC and reduced GSH of the liver tissues, implicating the presence of oxidative tissue damages. Eriobotrya japonica flower extracts as an antioxidant agent ameliorated oxidative stress in these tissues (see Figure 2). Based on research of Yokota et al. [34] Eriobotrya japonica seed extracts have strong antioxidative activities, lipid peroxidation inhibition activities, and are effective for the prevention and treatment of various diseases such as hepatopathy and nephropathy. Also, incubation with ethanol extract of loquat (Eriobotrya japonica) seeds significantly lowered the TBARS levels [36]. The decrease in the activi- ties of GST and GSH contents in liver is in agreement with the finding of Quig [37] who found that $\mathrm{Hg}$ can bind to GSH and cause irreversible excretion of up to two GSH molecules. In our study, glutathione levels of liver tissues were significantly decreased by $\mathrm{Hg}$ toxicity, and due to its antioxidant activities, EJFE administration reduced the Hg-induced oxidative damages and restored the GSH levels significantly. Mercuric chloride can induce $\mathrm{H}_{2} \mathrm{O}_{2}$ generation both in vitro and in vivo with the effects on the inner mitochondrial membrane [3]. Hydrogen peroxide produced is stimulus lipid peroxidation. In our study, $\mathrm{HgCl}_{2}$ significantly decreased GSH $(P<0.001)$, and increased MDA $(P<0.001)$ levels in rat livers in comparison with control groups. Administration of the EJFE (100 and $200 \mathrm{mg} / \mathrm{kg}$ ) significantly decreased MDA levels and increased GSH. In agreement with this study, Sharma et al. [38] reported the same results obtained from the effects of Spirulina fusifurmis on the oxidative stress induced $\mathrm{HgCl}_{2}$. Also, Huang et al. [39] reported that Eriobotrya japonica leaf extracts have antioxidative activities and their administrations to chronic bronchitis (CB) rats could decrease MDA concentration in alveolar macrophages (AM). Also, increased MDA levels in liver and decreased levels of TAC and GSH in stress groups $(\mathrm{Hg})$ are associated with accumulation mercuric contents in liver tissues about $14.47 \%(P<0.001)$ in comparison with control groups. The accumulation of $\mathrm{Hg}$ in the liver of groups receiving of $\mathrm{Hg}$ plus EJFE (100 and $200 \mathrm{mg} / \mathrm{kg}$ ) was adjusted to $13.49 \%$ and $13.93 \%(P<0.001)$ respectively, as compared with groups receiving $\mathrm{Hg}$ only. Our results are in contradiction with those of Su et al. [40]. They reported that selenium could decrease $\mathrm{Hg}$ contents in kidneys, but increase it in blood and liver.

\section{Conclusions}

Consequently, we demonstrated that $\mathrm{HgCl}_{2}$ induced toxicity involves oxidative damages in liver tissues in different groups. The hydro-alcoholic extracts of Eriobotrya japonica flowers possess an abundant free radical scavenging, antioxidative and hepatoprotective activities. ROS scavenging capacity of EJFE may be implicated in its hepatoprotective activities. Phytochemical analysis by HPLC of hydro-alcoholic extracts of Eriobotrya japonica flowers has shown the presence of a number of polyphenols such as hesperetin (as bioflavonoid) and gallic acid which are the major antioxidants. Based on the modeling of mercury accumulation in liver tissues, EJEF can decrease mercury accumulation in the liver and also it decreases the required time for reaching constant levels of mercury accumulation in the livers.

The authors express their gratitude to Dr. S. R. Nabavi, faculty member in Department of Chemistry of Mazandaran University, Babolsar, Iran for his kind help in modeling the studies. Authors are also thankful to Dr. Hadi Parsian for his performances in atomic absorption analysis of tissue samples in Department of Biochemistry, Medical University of Babol, Mazandaran, Iran. 
1 Langford N J, Ferner R E. Toxicity of mercury. J Hum Hypertens, 1999, 13: 651-656

2 Clarkson T W. The toxicology of mercury. Crit Rev Clin Lab Sci, 1997, 34: 369-403

3 Nath K A, Croatt A J, Likely S, et al. Renal oxidant injury and oxidant response induced by mercury. Kidney Int, 1996, 50: 1032-1043

4 Farina M, Soares F A, Zeni G, et al. Additive prooxidative effect of methylmercury and ebselen in liver from suckling rat pups. Toxicol Lett, 2004, 146: 227-235

5 Gstraunthaler G, Pfaller W, Kotanko P. Glutathione depletion and in vitro lipid peroxidation in mercury or maleate induced acute renal failure. Biochem Pharmacol, 1983, 32: 2969-2972

6 Zalups R K. Molecular interaction with mercury in the kidney. Pharmacol Rev, 2000, 52: 113-143

7 Stohs S J, Bagchi D. Oxidative mechanisms in the toxicity of metalions. Free Radic Biol Med, 1995, 18: 321-336

8 Huang Y L, Cheng S L, Lin T H. Lipid peroxidation in rats administrated with mercuric chloride. Biol Trace Elem Res, 1996, 52: 193-206

9 Girardi G, Elias M M. Mercuric chloride effects on rat renal redox enzymes activities: SOD protection. Free Radic Biol Med, 1995, 18: 61-66

10 Vaughan J G, Geissler C A. The New Oxford Book of Food Plants. New York: Oxford University Press, 1997. 110-111

11 de Tommasi N, Aquino R, de Simone F, et al. Plant metabolites, new sesquiterpene and ionone glycosides from Eryobotrya japonica. J Nat Prod, 1992, 55: 1025-1032

12 Ito H, Kobayashi E, Takamatsu Y, et al. Polyphenols from Eriobotrya japonica and their cytotoxicity against human oral tumor cell lines. Chem Pharm Bull, 2000, 48: 687-693

13 Ferreresa F, Gomesb D, Valentãob P, et al. Improved loquat (Eriobotrya japonica Lindl.) cultivars: Variation of phenolics and antioxidative potential. Food Chem, 2009, 114: 1019-1027

14 Peluso M R. Flavonoids attenuate cardiovascular disease, inhibit phosphodiesterase and modulate lipid homeostasis in adipose tissue and liver. Exp Biol Med, 2006, 231: 1287-1299

15 Hertog M C, Hollman P C H, Venema D P. Optimization of a quantitative HPLC determination of potentially anticarcinogenic flavonoids in vegetables and fruits. J Agric Food Chem, 1992, 40: 1591-1598

16 Sener G, Sehirli A O, Ayanoglu D, et al. Melatonin protects against mercury(II)-induced oxidative tissue damage in rats. Pharmacol Toxicol, 2003, 93: 290-296

17 Sener G, Sehirli O, Tozan A, et al. Ginkgo biloba extract protects against mercury(II)-induced oxidative tissue damage in rats. Food Chem Toxicol, 2007, 45: 543-550

18 Benzie I F, Strain J J. The ferric reducing ability of plasma (FRAP) as a measure of antioxidant power: The FRAP assay. Anal Biochem, 1996, 239: 70-76

19 Wills E D. Mechanism of lipid peroxide formation in animal tissues. Biochem J, 1966, 99: 667-676

20 Draper H H, Hadley M. MDA determination as an index of lipid peroxidation. Methods Enzymol, 1990, 186: 421-430

21 Ellman G L. Tissue sulfhydryl groups. Arch Biochem Biophys, 1959, 82: 70-77

22 Teeny F M. Rapid method for the determination of mercury in fish tissue by atomic absorption spectroscopy. J Agric Food Chem, 1975, 23: 668-671

23 Zumkley H, Bertram H P, Lison A, et al. Al, $\mathrm{Zn}$ and $\mathrm{Cu}$ concentration in plasma and tissue in chronic renal insufficiency. Clin Nephrol, 1979, 12: 18-21

24 Li X, Zhang J Q, Liu W, et al. Serum levels of perfluorinated compounds in the general population in Shenzhen, China. Chin Sci Bull, 2011, 56: 3092-3099

25 Thompson J, Lorber M, Toms L M L, et al. Use of simple pharmacokinetic modeling to characterize exposure of Australians to perfluorooctanoic acid and perfluorooctane sulfonic acid. Environ Int, 2010, 36: 390-397

26 Hong Y, Lin S, Jiang Y, et al. Variation in contents of total phenolics, flavonoids and antioxidant activities in the leaves of 11 Eriobotrya species. Plant Food Hum Nutr, 2008, 63: 200-204

27 Goyer R A. Toxic Effects of Metals, In: Klaassen C D, Amdur M O, Doull J, eds. Casarett and Doull's Toxicology. The Basic Science of Poisons. New York: McGraw-Hill Companies, 1996. 691-736

28 World Health Organization. Inorganic Mercury. Environmental Health Criteria 118. Geneva, 1991

29 Mahboob M, Shireen K F, Atkinson A, et al. Lipid peroxidation and oxidant enzyme activity in different organs of mice exposed to low level of mercury. J Environ Sci Health Part B, 2001, 36: 687-697

30 Alam M M, Javed K, Jafri M A. Effect of Rheum emodi (Revand Hindi) on renal functions in rats. J Ethnopharmacol, 2005, 96: $121-125$

31 Alam M S, Kaur G, Jabbar Z, et al. Eruca sativa seeds possess antioxidant activity and exert a protective effect on mercuric chloride induced renal toxicity. Food Chem Toxicol, 2007, 45: 910-920

32 Van Acker S A, Van Den Berg D J, Tromp M N, et al. Structural aspects of antioxidant activity of flavanoids. Free Radic Biol Med, 1996, 20: 331-342

33 Ebrahimzadeh M A, Bahramian F. Antioxidant activity of Crataegus pentagina subsp. elbursis fruits extracts used in traditional medicine in Iran. Pak J Biol Sci, 2009, 12: 413-419

34 Yokota J, Takuma D, Hamada A, et al. Scavenging of ractive oxigen species (ROS) by Eriobotrya japonica seed extract. Biol Pharm Bull, 2006, 29: 467-471

35 Alia M, Horcajo C, Bravo L, et al. Effect of grape antioxidant dietary fiber on the total antioxidant capacity and the activity of liver antioxidant enzymes in rats. Nutr Res, 2003, 23: 1251-1267

36 Koba K, Matsuoka A, Osada K, et al. Effect of loquat (Eriobotrya japonica) extracts on LDL oxidation. Food Chem, 2007, 104: 308-316

37 Quig D. Cysteine metabolism and metal toxicity. Alter Med Rev, 1998, 3: 262-270

38 Sharma M K, Sharma A, Kumar A, et al. Spirulina fusifurmis provides protection against mercuric chloride induced oxidative stress in Swiss albino mice. Food Chem Toxicol, 2007, 45: 2412-2419

39 Huang Y, Li J, Cao Q, et al. Anti-oxidative effect of triterpene acids of Eriobotrya japonica (Thunb.) Lindl. Leaf in chronic bronchitis rats. Life Sci, 2006, 78: 2749-2757

40 Su L, Wang M, Yin S T, et al. The interaction of selenium and mercury in the accumulations and oxidative stress of rat tissues. Ecotox Environ Safe, 2008, 70: 483-489

Open Access This article is distributed under the terms of the Creative Commons Attribution License which permits any use, distribution, and reproduction in any medium, provided the original author(s) and source are credited. 